\title{
Matrix metalloproteinases in impaired wound healing
}

\author{
This article was published in the following Dove Press journal: \\ Metalloproteinases In Medicine \\ 9 February 2015 \\ Number of times this article has been viewed
}

\section{Fabio Sabino \\ Ulrich auf dem Keller}

Institute of Molecular Health Sciences, Eidgenössische Technische Hochschule (ETH) Zürich, Zürich, Switzerland

Correspondence: Ulrich auf dem Keller Institute of Molecular Health Sciences, Eidgenössische Technische Hochschule (ETH) Zürich, Otto-Stern-Weg 7. $\mathrm{CH}-8093$ Zürich, Switzerland

Tel +4I 446333392

Fax +4 I 44633 I। 47

Email ulrich.aufdemkeller@biol.ethz.ch
Abstract: Cutaneous wound healing is a complex tissue response that requires a coordinated interplay of multiple cells in orchestrated biological processes to finally re-establish the skin's barrier function upon injury. Proteolytic enzymes and in particular matrix metalloproteinases (MMPs) contribute to all phases of the healing process by regulating immune cell influx, facilitating migration of fibroblasts and keratinocytes, and remodeling of the scar tissue. As a result of these pleiotropic functions in the healing skin wound, uncontrolled activities of MMPs are associated with impaired wound healing, a growing health problem in Western countries due to increased life expectancies and rising rates of underlying diseases, such as diabetes. However, detailed mechanisms have been only partially unraveled, and new diagnostic tools and more targeted therapies are urgently needed. In this review, we discuss the roles of MMPs in acute and chronic wound healing and summarize current therapeutic approaches aiming at inhibiting aberrant MMP activities in healing disorders.

Keywords: skin, chronic wounds, proteases, MMPs

\section{Overview of cutaneous wound healing}

The skin is the largest organ of the human body. ${ }^{1}$ It consists of two layers (dermis and epidermis), hair follicles, sebaceous and sweat glands, and serves as a structural and functional barrier of the organism against the surrounding environment and prevent dehydration. ${ }^{2}$ Upon injury, the skin undergoes a complex process of healing that involves blood and parenchymal cells, growth factors, cytokines, proteases, and extracellular matrix (ECM) proteins that finally leads to skin repair. This process can be divided into three overlapping phases: hemostasis/inflammation, proliferation, and remodeling. ${ }^{3-6}$

\section{Hemostasis and inflammatory response}

Platelets are the first cells to arrive at the site of damage, and they play important roles in hemostasis, inflammation, re-epithelialization, fibroplasia, and angiogenesis. ${ }^{7}$ During the first minutes after wounding (5-10 minutes), platelets contribute to vasoconstriction to reduce blood loss and aggregate upon initiation of the coagulation cascade. A platelet plug and a clot of crosslinked fibrin, plasma fibronectin, ECM proteins, vitronectin, and thrombospondins are formed, establishing a temporary closure of the wound. The blood clot acts as a reservoir for cytokines and growth factors, and constitutes a provisional scaffolding matrix for migrating leukocytes, fibroblasts, and endothelial cells. After the initial vasoconstriction, vessels are dilated, and capillary permeability increases (20 minutes after wounding), allowing more platelets and inflammatory cells 
to reach the provisional wound matrix. As a consequence, the wound appears red and swollen.

Minutes after injury, neutrophils migrate to the wound site in response to complement activation, degranulation of platelets, and bacterial degradation, and clean the affected area from external particles and microorganisms, dying a few days later. ${ }^{8}$ Neutrophils also release chemoattractants and proinflammatory molecules, such as tumor necrosis factor alpha, interleukin (IL)-1 $\beta$, and IL-6 to amplify the inflammatory response. Soon after, mast cells and monocytes infiltrate the wound (within 2-3 days), where the monocytes differentiate into macrophages and phagocyte pathogens, remaining neutrophils, and tissue debris. Macrophages release additional growth factors and cytokines that induce cell migration, proliferation, and production of new ECM.

\section{Proliferation}

The proliferative phase lasts 2-10 days after wounding, is mainly characterized by proliferation and migration of cells, and involves re-epithelialization, angiogenesis, and fibroplasia. Growth factors and cytokines released by inflammatory and epithelial cells at the wound edges induce proliferation and migration of keratinocytes to cover the wound with a new epidermis. ${ }^{9}$ Approximately 4 days after injury, the wound starts to be filled with new stroma, also called granulation tissue due to its high density in fibroblasts, granulocytes, macrophages, capillaries, and collagen. In response to various growth factors and promoted by thrombin, blood vessels in proximity of the wound start sprouting and give rise to new vessels that provide nutrients and oxygen to the growing tissue and are responsible for its granular appearance. Concomitantly, fibroblasts and macrophages migrate to the wound site. Fibroblasts proliferate and produce large amounts of collagen and ECM molecules (fibroplasia), which replace the provisional matrix. Fibroblasts gradually differentiate into myofibroblasts, which secrete ECM and contract, reducing the size of the wound. ${ }^{10}$ This new matrix plays an essential role in the support of endothelial cell migration and vessel growth. Macrophages release growth factors and cytokines that further stimulate fibroplasia and angiogenesis.

\section{Remodeling}

The remodeling phase is the last stage of skin repair, occurs from 2-3 weeks to 2 years after injury, and is mainly characterized by wound contraction and reorganization of the ECM. Wound contraction is mostly mediated by myofibroblasts and reaches its maximum 2 weeks after wounding. The granulation tissue undergoes a remodeling process by degradation of the majority of collagen type III fibers that were synthesized during the proliferative phase and synthesis of the stronger form of collagen type I. This process is mainly mediated by matrix metalloproteinases (MMPs) secreted by macrophages, epidermal cells, endothelial cells, and fibroblasts. ${ }^{11,12}$ Most myofibroblasts, macrophages, and endothelial cells undergo apoptosis or leave the injured site, stopping formation of granulation tissue and ceasing angiogenesis. These changes in the type of collagen at the wound site, along with closure of the wound and reduction in number of vessels, are responsible for the replacement of granulation tissue by a scar. Scar tissue is less elastic than unwounded skin and lacks appendage structures, such as hair follicles, sebaceous glands, and sweat glands.

\section{MMPs in skin repair}

MMPs are a family of endoproteinases consisting of the "classical" MMPs, the membrane-bound MMPs, the ADAMs (a disintegrin and metalloproteinases, otherwise known as adamlysins), and the ADAMTSs (ADAMs with thrombospondin motif). ${ }^{11,13}$ The classical MMPs comprise 24 secreted and surface-bound, zinc-dependent enzymes that are subdivided into collagenases (MMP-1, MMP-8, MMP-13, and MMP-18), gelatinases (MMP-2 and MMP-9), stromelysins (MMP-3, MMP-10, and MMP-11), matrilysins (MMP-7 and MMP-26), membrane-bound MMPs (MMP-14, MMP-15, MMP-16, MMP-17, MMP-24, and MMP-25), and other MMPs (MMP-12, MMP-19, MMP-20, MMP-21, MMP-23, MMP-27, and MMP-28). Since the discovery of MMPs by Gross and Lapiere in tadpole tails, these enzymes have been primarily implicated in the degradation of ECM. ${ }^{14}$ However, with the availability of genetically engineered models, it was observed that MMPs have a variety of other non-matrix substrates, such as cytokines, chemokines, growth factors, their binding proteins, and receptors. ${ }^{15}$

The activity of MMPs is tightly regulated both at the transcriptional and at the post-transcriptional level. ${ }^{16,17}$ Several cell types, such as keratinocytes, fibroblasts, endothelial cells, and inflammatory cells can control MMP activity by regulation of gene expression in response to cytokines, growth factors, hormones, oncogenes, and contact with other cells or ECM. For some MMPs, regulation also occurs through modification of chromatin, stabilization of messenger RNA and during secretion of the enzyme. ${ }^{16,18}$ Importantly, all MMPs are synthesized as inactive zymogens and require activation by other proteases, such as plasminogen, furin, or other MMPs. ${ }^{18,19}$ Finally, active MMPs are controlled by tissue inhibitors of metalloproteinases (TIMPs), a family of 
four secreted proteins (TIMP-1, $-2,-3$, and -4 ) that reversibly inhibit MMP activity. ${ }^{20}$

\section{MMPs in acute wound healing}

While levels of MMPs are very low in normal skin, their expression and activity strongly increase upon injury. ${ }^{11,12,18,21-23}$ There is evidence for increased gene expression during wound repair of MMP-2, MMP-3, MMP-9, MMP-11, MMP-12, MMP-13, and MMP-14. In the first day after wounding, MMPs are secreted by inflammatory cells and cleanse the wound from damaged ECM and tissue. MMPs also play an important role in the formation of granulation tissue by acting on basement membranes of arterioles. This helps migrating endothelial cells from new vessels to reach the wound bed. In response to growth factors, endothelial cells of existing vessels activate signaling cascades that culminate in the release of MMPs to allow for endothelial proliferation and migration through digestion of tissue matrix. Similarly, migrating keratinocytes secrete MMP-1, MMP-2, MMP-9, and MMP-10 that modulate keratinocyte motility by degradation of proteins involved in cell-cell and cell-matrix adhesion, allowing re-epithelialization to occur. ${ }^{24-26}$ During the remodeling phase, fibroblasts and myofibroblasts release MMPs that degrade irregular portions of matrix, which constitute the scar and help in contraction of the newly formed scar tissue. Importantly, MMPs also regulate the inflammatory response as well as cell-cell and cell-matrix signaling by activation or inactivation of cytokines, chemokines, and growth factors. ${ }^{27}$ Thus, MMPs play crucial roles during all phases of cutaneous wound healing, and as a consequence, uncontrolled activity of these proteases is thought to be one of the main causes for healing impairments. ${ }^{21,28,29}$

\section{MMPs in chronic wounds}

Chronic wounds (non-healing wounds or chronic ulcers) represent a growing health problem in Western countries due to aging populations or underlying conditions, such as diabetes, obesity, infection, and poor nutrition. ${ }^{30,31}$ Non-healing wounds develop when the healing process fails to proceed through all normal stages of cutaneous repair, but is stalled in a pathologic state of inflammation associated with impaired neovascularization, reduced synthesis of collagen, increased proteolytic activity, and defective macrophage function. ${ }^{29,32}$

Chronic wounds are characterized by elevated levels and activities of collagenases (MMP-1 and MMP-8) and gelatinases (MMP-2 and MMP-9) and concomitant abnormal low levels of TIMPs. ${ }^{33,34}$ If the tightly controlled equilibrium of MMP activity and inhibition is disturbed, the wound progresses to a state of increased ECM degradation, alteration of cytokine profile, and degradation of growth factors, culminating in delayed or absent wound closure. ${ }^{18,35}$ For example, activities of MMP-2 and MMP-9 are several times higher in non-healing than in healing wounds, and inhibition of these enzymes helps to enhance the healing process. However, if levels of MMP-9 become lower than normal, epithelialization is delayed. ${ }^{36}$

It was observed that most of the collagenase activity is derived from MMP-8; MMP-8 levels can be 50-100 times higher in chronic than in normal wounds. ${ }^{33,37}$ This enzyme is secreted by neutrophils, which in chronic wounds do not undergo rapid apoptosis but persist during the entire healing process as a result of chronic inflammation..$^{35}$ Excessive neutrophil activation also leads to increased production of neutrophil-derived elastase that degrades connective tissue molecules and activates MMPs. ${ }^{38}$ MMP-8 degrades collagen and potentially influences the pathophysiology of the wound by degradation of fibronectin, $\alpha 1$-antiproteinase, $\alpha 2$-macroglobulin, growth factors, such as transforminggrowth factor (TGF) $\beta$ and platelet-derived growth factor (PDGF), and products of fibroblast synthesis. ${ }^{35}$ This chain of events disrupts the equilibrium between synthesis and remodeling of ECM components, which is a key determinant for successful skin repair. ${ }^{28}$

It has been shown that fibronectin is present at high levels in chronic wounds. ${ }^{36}$ Fibronectin is a glycoprotein that interacts with cytokines, the ECM, and with integrins of different cell types, playing important roles in cell-matrix interactions, fibrin clot stabilization, formation of granulation tissue, and cell migration. ${ }^{39}$ However, the fibronectin found in chronic wounds differs from fibronectin present in acute wounds, since it is highly fragmented and degraded. It is believed that MMP-9 is responsible for digestion of fibronectin in chronic wounds and that the resultant fragments may exert biological roles, which differ from the natural function of full-length fibronectin. These roles include modulation of MMP activity as well as cell migration and proliferation, creating a state of persistent inflammation, tissue destruction, and leukocyte infiltration. ${ }^{36}$

\section{Targeting MMPs in chronic wound healing}

Various studies showed enhanced activity of MMPs in healing impairments and detrimental effects of the associated proteolytic environment for normal wound healing. Therefore, numerous treatments have been developed that 
aim at targeting MMPs in chronic wounds to reduce their negative effects (Table 1).

\section{Tetracyclines}

Tetracyclines are a group of antibiotics with anti-inflammatory, anti-apoptotic, anti-proteolytic, anti-angiogenic, and antimetastatic properties. ${ }^{40}$ Tetracyclines also inhibit MMP activity and connective tissue degradation by deprivation and chelation of divalent cations $\left(\mathrm{Zn}^{2+}\right.$ and $\mathrm{Ca}^{2+}$ are fundamental for MMP activity) and through indirect mechanisms, such as downregulation of MMP synthesis and inhibition of proinflammatory mediators and growth factors that increase MMP expression. ${ }^{41}$ These characteristics raised interest in tetracyclines for other applications besides antimicrobial purposes, and therefore they have been widely used to treat several noninfectious diseases, such as rheumatoid arthritis, acne, periodontitis, rosacea, and neutrophilic disorders. Tetracyclines have also been tested for the treatment of chronic wounds, and most of the initial studies focused on two semi-synthetic tetracyclines: minocycline and doxycycline. ${ }^{42-45}$

Minocycline is an antibiotic semi-synthetically synthesized from the original tetracyclines, which was shown by in vivo and in vitro studies to inhibit the gelatinases MMP-2 and MMP-9, the collagenases MMP-1, MMP-8, and MMP-13, and stromelysin (MMP-3), apparently through downregulation of expression of these enzymes and with special sensitivity for MMP-9. ${ }^{46}$ In addition, minocycline inhibits the inducible version of nitric oxide synthase (iNOS), a proinflammatory enzyme that is known to induce catabolic events mediated by IL-1 $\beta$ and to upregulate expression of MMPs. ${ }^{41} \mathrm{~A}$ recent study performed in patients with chronic venous leg ulcers showed that inhibition of MMPs and ECM degradation through oral administration of minocycline was beneficial for wound healing. ${ }^{47}$

Doxycycline is a more potent inhibitor of MMPs than original tetracyclines and has several advantages over minocycline, particularly better pharmacokinetics, making it safer for the patient. ${ }^{44}$ It was reported to inhibit MMP-1 and MMP-8 with half maximal inhibitory concentration values of $25 \mathrm{mM}$ and $300 \mathrm{mM}$, respectively, and to inhibit both the activity and the secretion of MMP-2 and MMP-9.32,42,48 Several clinical trials have reported beneficial effects of doxycycline for treatment of chronic wounds, which have been associated with inhibition of MMPs. However, bacterial infection may also play an important role for the development of chronic wounds, and thus the use of doxycycline does not allow studying only the effect of MMP inhibition on impaired healing. Moreover, the use of doxycycline raises concerns regarding development of antibiotic-resistant strains of bacteria. ${ }^{43,45}$

Due to the limitations of naturally occurring tetracyclines, several chemical modifications were added to the original

Table I Overview of current therapies for inhibition of elevated MMP activities in chronic wounds

\begin{tabular}{|c|c|c|}
\hline Treatment method & Mechanism of action & Limitations \\
\hline \multicolumn{3}{|l|}{ Tetracyclines } \\
\hline Minocycline & Inhibition of MMP-I, $-2,-3,-8$, and -9 , and iNOS ${ }^{41}$ & $\begin{array}{l}\text { Gastrointestinal toxicity; }{ }^{44} \text { possibility } \\
\text { of development of antibiotic-resistant } \\
\text { strains of bacteria }{ }^{43}\end{array}$ \\
\hline Doxycycline & Inhibition of MMP-I, $-2,-8$, and $-935,42$ & Development of antibiotic resistance ${ }^{43}$ \\
\hline $\begin{array}{l}\text { Chemically modified } \\
\text { tetracyclines (CMTs) }\end{array}$ & $\begin{array}{l}\text { Inhibition of MMP-I, }-2,-3,-8,-9,-10,-1 \mathrm{I},-13 \text {, } \\
\text { MT-MMPs, and neutrophil elastase }{ }^{42-44}\end{array}$ & Not well studied \\
\hline \multicolumn{3}{|l|}{ Silver-containing agents } \\
\hline $\begin{array}{l}\text { Silver nitrate, silver } \\
\text { sulfadiazine }\end{array}$ & Antimicrobial properties; ${ }^{53}$ reduction of infection ${ }^{53}$ & $\begin{array}{l}\text { Inactivation by chloride ions present } \\
\text { in wound exudate; } ;^{53} \text { cytotoxicity }{ }^{54}\end{array}$ \\
\hline Silver nanoparticles & $\begin{array}{l}\text { Antimicrobial properties; }{ }^{53} \text { reduction of infection; }{ }^{53} \\
\text { anti-inflammatory properties and decreased activity } \\
\text { of gelatinases (mainly MMP-9) }{ }^{36}\end{array}$ & Possible cytotoxicity ${ }^{55}$ \\
\hline Collagen dressing agents & $\begin{array}{l}\text { Functions as alternative substrate for MMPs } \\
\text { and neutrophil elastase; }{ }^{38,61} \text { possibility addition } \\
\text { of bioactive components to the dressing agent }{ }^{58}\end{array}$ & $\begin{array}{l}\text { Optimal collagen source and bioactive } \\
\text { components not elucidated }\end{array}$ \\
\hline $\begin{array}{l}\text { Negative pressure wound } \\
\text { therapy (NPWT) }\end{array}$ & $\begin{array}{l}\text { Increased formation of granulation tissue } \\
\text { and wound bed preparation, faster reduction of wound } \\
\text { area, increased cell proliferation and reduction } \\
\text { of edema; }{ }^{68,69} \text { possible reduction of levels of } \text { MMPs }^{69}\end{array}$ & $\begin{array}{l}\text { Mechanisms responsible for observed } \\
\text { effects not well understood }{ }^{67}\end{array}$ \\
\hline Superabsorbers & $\begin{array}{l}\text { Reduction of MMP activity by absorption of exudate } \\
\text { and chelation of } \mathrm{Zn}^{2+} \text { and } \mathrm{Ca}^{2+} \text { ions }{ }^{71,72}\end{array}$ & General rather than specific effect \\
\hline
\end{tabular}

Abbreviations: MMP, matrix metalloproteinase; MT-MMPs, membrane-bound MMPs; iNOS, nitric oxide synthase. 
molecules, aiming at removing the antimicrobial activity without interfering with the other functionalities. These chemically modified tetracyclines (CMTs) maintained the non-antimicrobial properties of the original compounds, such as improvement of anti-angiogenesis, regulation of release of inflammatory cytokines, inhibition or activation of leukocyte chemotaxis, and anti-oxidative activities, but they did not cause gastrointestinal toxicity after long-term systemic administration. ${ }^{49}$ This characteristic allows higher plasma concentrations of the drug over a longer period of time. Several studies also showed that CMTs are able to inhibit neutrophil elastase and MMPs, namely gelatinases (MMP-2 and MMP-9), stromelysins (MMP-3, MMP-10, and MMP-11), collagenases (MMP-1, MMP-8, and MMP-13), and membrane-bound MMPs. ${ }^{42-44}$ The effects of topically applied CMTs for the treatment of chronic wounds are not well documented yet. However, one study performed with diabetic rats showed increased formation of granulation tissue, enhanced re-epithelialization, and decreased activity of collagenases and gelatinases in CMT-2 treated wounds. ${ }^{50}$ Hence, CMTs may be a good alternative to natural tetracyclines for treatment of healing impairments, but more research is still needed in this area.

\section{Silver based treatments}

MMP-9 has been reported as a main enzyme responsible for matrix degradation in chronic wounds, and abundances of this protease can be up to 25 times higher than in acute wounds. ${ }^{51}$ Moreover, the activity of MMP-9 in chronic wounds was found to be a better indicator for chronicity than the total proteolytic activity in wound fluid. Nonetheless, studies exploring specific MMP-9 inhibition during wound healing are still scarce. ${ }^{36,43}$

Silver nitrate and silver sulfadiazine have been widely used against infection and have also been applied as active agents in wound dressings. ${ }^{52}$ However, there are concerns regarding possible cytotoxicity of silver-containing materials. Silver causes precipitation of DNA within bacteria and binds to membranes and cell wall proteins. However, silver also reacts with chloride present in wound exudate and thus could precipitate and become inactive against pathogens, requiring more frequent changes of wound dressing. To overcome this limitation, silver nanoparticles, nanocrystalline silver (NCS), were developed. ${ }^{53,54}$ These nanoparticles release uncharged clusters of silver atoms $\left(\mathrm{Ag}^{0}\right)$ and $\mathrm{Ag}^{+}, \operatorname{not} \mathrm{Ag}^{5+}$ as in other silver-containing dressing materials. This uncharged silver reacts slower with chloride ions, increasing efficacy of action. ${ }^{53,55} \mathrm{NCS}$ proved to be efficient against fungi and bacteria, and it was shown to accelerate wound healing in pigs. ${ }^{56}$ However, the use of NCS is not undisputed. While tests performed in cultured keratinocytes and fibroblasts describe cytotoxic effects induced by NCS, results in human wounds are not conclusive. In some types of wounds, NCS promoted wound healing, but it delayed the healing process in others. ${ }^{55}$

In addition to NCS's capacity to reduce infection, it also has anti-inflammatory properties mediated by decreased expression of proinflammatory cytokines, increased apoptosis of inflammatory cells, and decreased activity of gelatinases, mainly MMP-9. ${ }^{55}$ At first, researchers associated the beneficial effects of NCS for wound healing with the antimicrobial properties of the dressing agent, but now research is starting to focus on the anti-inflammatory properties, since inhibition of MMP-9 has been suggested as a method to control inflammation. ${ }^{36}$

\section{Collagen dressing agents}

Collagen is produced by fibroblasts, and it is the main component of the ECM and the most abundant protein in the human body. ${ }^{38,57}$ It provides structural support for tissues, such as the skin, tendons, bones, cartilage, blood vessels, and ligaments. ${ }^{58}$ During wound healing, collagen functions as a scaffold for fibroblasts and keratinocytes and promotes debridement, cell migration, angiogenesis, epithelialization, proliferation, differentiation, and cell survival. ${ }^{58-60}$ Chronic wounds are characterized by impaired recruitment of fibroblasts, reduced collagen deposition, and enhanced activity of MMPs that, taken together, result in the destructive cycle of wound chronicity. ${ }^{38}$ The idea of using collagenbased dressing agents is to provide alternative substrates for MMPs, reducing the degradation of endogenous collagen and allowing the wound to heal normally. ${ }^{61}$ In addition, collagen-based dressings can also function as a substrate for elastase, which is relatively unspecific and also increases in activity during wound healing. ${ }^{38}$ In the Second World War, collagen sutures and extruded fibers were already being used to cover wounded skin, and since then several new collagen-based dressing agents have been developed. ${ }^{58}$ The more recent collagen-based dressing agents have been shown to improve healing of acute and chronic wounds in pigs. ${ }^{61,62}$ Nowadays, collagen dressings can contain human-derived or animal-derived collagen, both in native or denatured states (described as gelatin). While human-derived collagen is associated with fewer immunological problems, it is more expensive than animal-derived collagen (such as porcine or bovine collagen), and there is still some concern about the 
possibility of prion disease transmitted by these types of collagen. ${ }^{63}$ Regarding the state of the collagen, it is possible that some of the benefits of collagen on modulation of cells may be lost with denatured molecules. Moreover, denatured collagen is also degraded faster. ${ }^{38}$

Studies have also been performed with collagen-based dressings enriched with additional bioactive components, such as growth factors, chelators, antibiotics, or antioxidants. ${ }^{58}$ A study conducted using an infected excisional wound model in rats tested effects of a collagen-based dressing material that releases doxycycline into the wound site. Thereby, the authors tried to target problems originating from infection and from protein degradation at the same time. The study showed faster healing in the treatment than in the control group, which was associated with a higher synthesis of collagen and reduced activity of MMP-2, MMP-8, and MMP-9. ${ }^{64}$ Gottrup et al performed a clinical trial in which patients with diabetic foot ulcers were treated with a dressing agent containing collagen, oxidized regenerated cellulose, and silver. This study showed improved healing in the treatment group, with less infection, lower activity of MMP-9 and elastase, and improved wound closure. ${ }^{65}$

Taken together, collagen-based dressing materials have the potential to improve wound healing, but more research is still necessary to optimize the type and source of collagen to use, and to assess if patients would benefit from addition of any other component, such as antibiotics, growth factors, or other types of bioactive agents that might also be directed against enhanced MMP activity in chronic wounds.

\section{Negative pressure wound therapy and superabsorbers}

Negative pressure wound therapy (NPWT) describes a technique that uses reticulated open-cell foams, which are placed onto the wound site and covered with a semi-occlusive film. The dressing is connected to a therapy unit that delivers vacuum pressure to the wound. ${ }^{66,67}$ This method has been widely used during the last 15 years and shows positive outcomes for wound healing in terms of increased formation of granulation tissue and wound bed preparation, faster reduction of wound area, increased cell proliferation, and reduction of edema. ${ }^{68,69}$ The mechanisms underlying the effects of NPWT are not completely understood, but several ideas have been proposed. Primarily, it is thought that NPWT leads to macro- and micro-deformation of the wound, which facilitates wound closure, and that it maintains a controlled environment during healing by removal of excess wound fluid. ${ }^{67}$ Given the increased proteolytic environment in chronic wounds, it has also been hypothesized that NPWT could reduce levels of MMPs by active reduction of proteaserich wound fluid. A study by Mouës et al demonstrated lower levels of pro-MMP-9 and a lower MMP-9/TIMP-1 ratio in patients undergoing NPWT compared to patients subjected to conventional therapies. ${ }^{69}$ However, more studies must be performed in order to understand if the beneficial effects of NPWT are related to reduced activity of MMPs.

A similar effect on removal of detrimental MMPs from chronic wound environments has been demonstrated for superabsorbent hydrogel wound dressings. ${ }^{70,71}$ Through their capacity to very efficiently absorb large amounts of fluids, these dressings are very effective in the cleansing phase of wound treatment, when MMP activity is particularly high. In addition to reducing MMP activity in the wound by passive diffusion of exudate, superabsorbers directly bind these proteases as well as $\mathrm{Zn}^{2+}$ and $\mathrm{Ca}^{2+}$ ions that are required for their proteolytic activity. These additional activities toward MMPs significantly increase positive effects of specific types of superabsorbers compared to amorphous hydrogel dressing with no protease-inhibiting activity. ${ }^{72}$ Thus, superabsorbent hydrogels hold great promise for re-establishing a balanced proteolytic milieu in hard-to-heal wounds and as a prerequisite for normal healing progression.

\section{Conclusion}

Wound healing is a complex process that comprises three overlapping phases: hemostasis/inflammation, proliferation, and remodeling. These processes implicate several different cell types as well as ECM synthesis and degradation, growth factor activity, and bioactive actions of inflammatory mediators. Proteases play a pivotal role during wound healing, whereby MMPs have gained special attention due to a correlation between unbalanced MMP activity and progression of chronic wounds. Thus, research has focused on developing strategies to reduce the negative effects of enhanced MMP activity in impaired healing. Although many inhibitors of MMPs have been synthesized, only a few have been approved for treatment. These difficulties are associated with important functions of MMPs in normal wound healing and physiological processes in general, such as processing of cytokines, chemokines, and growth factors, and regulation of apoptosis and immune responses. Therefore, the modulation of MMP activity must be controlled to avoid undesirable outcomes. ${ }^{73}$ The knowledge about the level and activity of proteases (in particular MMPs) in each particular wound could allow to predict healing progression and to devise specific treatments for individual patients. 
However, a good point-of-care test is not available yet. Systagenix Wound Management LLC commercialized the Woundchek ${ }^{\mathrm{TM}}$ test to measure proteolytic activity in chronic wounds, but effective therapeutic options to reduce that activity are still limited. ${ }^{37,74}$

\section{Acknowledgments}

UadK acknowledges support by a project grant from the Swiss National Science Foundation (31003A_140726), by a grant from the European Commission (Marie Curie International Reintegration Grant; FP7-PEOPLE- 2010-RG/ SkiNterminomics), and an unrestricted research grant from Paul Hartmann AG. FS is supported by a predoctoral fellowship from the Portuguese Foundation for Science and Technology (FCT) (SFRH/BD/88564/2012).

\section{Disclosure}

The authors report no conflicts of interest in this work.

\section{References}

1. Kanitakis J. Anatomy, histology and immunohistochemistry of normal human skin. Eur J Dermatol. 2002;12(4):390-399.

2. Proksch E, Brandner JM, Jensen JM. The skin: an indispensable barrier. Exp Dermatol. 2008;17(12):1063-1072.

3. Gurtner GC, Werner S, Barrandon Y, Longaker MT. Wound repair and regeneration. Nature. 2008;453(7193):314-321

4. Martin P. Wound healing - aiming for perfect skin regeneration. Science. 1997;276(5309):75-81.

5. Singer AJ, Clark RA. Cutaneous wound healing. $N$ Engl J Med. 1999;341(10):738-746.

6. Schäfer M, Werner S. Cancer as an overhealing wound: an old hypothesis revisited. Nat Rev Mol Cell Biol. 2008;9(8):628-638.

7. Nurden AT, Nurden P, Sanchez M, Andia I, Anitua E. Platelets and wound healing. Front Biosci. 2008;13:3532-3548.

8. Eming SA, Krieg T, Davidson JM. Inflammation in wound repair: molecular and cellular mechanisms. J Invest Dermatol. 2007;127(3): 514-525.

9. Werner S, Grose R. Regulation of wound healing by growth factors and cytokines. Physiol Rev. 2003;83(3):835-870.

10. Hinz B. Formation and function of the myofibroblast during tissue repair. J Invest Dermatol. 2007;127(3):526-537.

11. Page-McCaw A, Ewald AJ, Werb Z. Matrix metalloproteinases and the regulation of tissue remodelling. Nat Rev Mol Cell Biol. 2007;8(3): 221-233.

12. Parks WC. Matrix metalloproteinases in repair. Wound Repair Regen. 1999;7(6):423-432.

13. Edwards DR, Handsley MM, Pennington CJ. The ADAM metalloproteinases. Mol Aspects Med. 2008;29(5):258-289.

14. Gross J, Lapiere CM. Collagenolytic activity in amphibian tissues: a tissue culture assay. Proc Natl Acad Sci U S A. 1962;48:1014-1022.

15. Rodríguez D, Morrison CJ, Overall CM. Matrix metalloproteinases: what do they not do? New substrates and biological roles identified by murine models and proteomics. Biochim Biophys Acta. 2010;1803(1): 39-54.

16. Sternlicht MD, Werb Z. How matrix metalloproteinases regulate cell behavior. Annu Rev Cell Dev Biol. 2001;17:463-516.

17. Overall CM, López-Otín C. Strategies for MMP inhibition in cancer: innovations for the post-trial era. Nat Rev Cancer. 2002;2(9): $657-672$.
18. Martins VL, Caley M, O’Toole EA. Matrix metalloproteinases and epidermal wound repair. Cell Tissue Res. 2013;351(2):255-268.

19. Malemud CJ. Matrix metalloproteinases (MMPs) in health and disease: an overview. Front Biosci. 2006;11:1696-1701.

20. Khokha R, Murthy A, Weiss A. Metalloproteinases and their natural inhibitors in inflammation and immunity. Nat Rev Immunol. 2013;13(9): 649-665.

21. McCarty SM, Cochrane CA, Clegg PD, Percival SL. The role of endogenous and exogenous enzymes in chronic wounds: a focus on the implications of aberrant levels of both host and bacterial proteases in wound healing. Wound Repair Regen. 2012;20(2):125-136.

22. Madlener M, Parks WC, Werner S. Matrix metalloproteinases (MMPs) and their physiological inhibitors (TIMPs) are differentially expressed during excisional skin wound repair. Exp Cell Res. 1998;242(1): 201-210.

23. Gill SE, Parks WC. Metalloproteinases and their inhibitors: regulators of wound healing. Int J Biochem Cell Biol. 2008;40(6-7): 1334-1347.

24. Stadelmann WK, Digenis AG, Tobin GR. Physiology and healing dynamics of chronic cutaneous wounds. Am J Surg. 1998; 176(2A Suppl):26S-38S.

25. O'Toole EA. Extracellular matrix and keratinocyte migration. Clin Exp Dermatol. 2001;26(6):525-530.

26. Chen P, Parks WC. Role of matrix metalloproteinases in epithelial migration. J Cell Biochem. 2009;108(6):1233-1243.

27. Parks WC, Wilson CL, López-Boado YS. Matrix metalloproteinases as modulators of inflammation and innate immunity. Nat Rev Immunol. 2004;4(8):617-629.

28. McCarty SM, Percival SL. Proteases and delayed wound healing. Adv Wound Care (New Rochelle). 2013;2(8):438-447.

29. Ren Y, Gu G, Yao M, Driver VR. Role of matrix metalloproteinases in chronic wound healing: diagnostic and therapeutic implications. Chin. Med J (Engl). 2014;127(8):1572-1581.

30. Sen CK, Gordillo GM, Roy S, et al. Human skin wounds: a major and snowballing threat to public health and the economy. Wound Repair Regen. 2009;17(6):763-771.

31. Li J, Chen J, Kirsner R. Pathophysiology of acute wound healing. Clin Dermatol. 2007;25(1):9-18.

32. Menke NB, Ward KR, Witten TM, Bonchev DG, Diegelmann RF. Impaired wound healing. Clin Dermatol. 2007;25(1):19-25.

33. Armstrong DG, Jude EB. The role of matrix metalloproteinases in wound healing. J Am Podiatr Med Assoc. 2002;92(1):12-18.

34. Falanga V. The chronic wound: impaired healing and solutions in the context of wound bed preparation. Blood Cells Mol Dis. 2004;32(1): 88-94.

35. Menke MN, Menke NB, Boardman CH, Diegelmann RF. Biologic therapeutics and molecular profiling to optimize wound healing. Gynecol Oncol. 2008;111(2 Suppl):S87-S91.

36. Widgerow AD. Chronic wound fluid - thinking outside the box. Wound Repair Regen. 2011;19(3):287-291.

37. Gibson DJ, Schultz GS. Molecular wound assessments: matrix metalloproteinases. Adv Wound Care (New Rochelle). 2013;2(1): 18-23.

38. Fleck CA, Simman R. Modern collagen wound dressings: function and purpose. J Am Col Certif Wound Spec. 2010;2(3):50-54.

39. Lenselink EA. Role of fibronectin in normal wound healing. Int Wound J. 2013;9999(9999).

40. Nelson ML, Levy SB. The history of the tetracyclines. Ann N Y Acad Sci. 2011;1241:17-32.

41. Garrido-Mesa N, Zarzuelo A, Gálvez J. What is behind the non-antibiotic properties of minocycline? Pharmacol Res. 2013;67(1):18-30.

42. Acharya MR, Venitz J, Figg WD, Sparreboom A. Chemically modified tetracyclines as inhibitors of matrix metalloproteinases. Drug Resist Updat. 2004;7(3):195-208.

43. Monk E, Shalita A, Siegel DM. Clinical applications of non-antimicrobial tetracyclines in dermatology. Pharmacol Res. 2011;63(2): 130-145. 
44. Tilakaratne A, Soory M. Anti-inflammatory actions of adjunctive tetracyclines and other agents in periodontitis and associated comorbidities. Open Dent J. 2014;8:109-124.

45. Serra R, Gallelli L, Buffone G, et al. Doxycycline speeds up healing of chronic venous ulcers. Int. Wound J. Epub April 5, 2013.

46. Redin GS. Antibacterial activity in mice of minocycline, a new tetracycline. Antimicrob Agents Chemother (Bethesda). 1966;6: 371-376.

47. Serra R, Grande R, Buffone G, Gallelli L, De Franciscis S. The effects of minocycline on extracellular matrix in patients with chronic venous leg ulcers. Acta Phlebol. 2013;14:99-107.

48. Suomalainen K, Halinen S, Ingman T, et al. Tetracycline inhibition identifies the cellular sources of collagenase in gingival crevicular fluid in different forms of periodontal diseases. Drugs Exp Clin Res. 1992;18(3):99-104.

49. Cazalis J, Tanabe S, Gagnon G, Sorsa T, Grenier D. Tetracyclines and chemically modified tetracycline-3 (CMT-3) modulate cytokine secretion by lipopolysaccharide-stimulated whole blood. Inflammation. 2009;32(2):130-137.

50. Ramamurthy NS, Kucine AJ, McClain SA, McNamara TF, Golub LM. Topically applied CMT-2 enhances wound healing in streptozotocin diabetic rat skin. Adv Dent Res. 1998;12(2):144-148.

51. Yager DR, Zhang LY, Liang HX, Diegelmann RF, Cohen IK. Wound fluids from human pressure ulcers contain elevated matrix metalloproteinase levels and activity compared to surgical wound fluids. J Invest Dermatol. 1996;107(5):743-748.

52. Leaper DJ. Silver dressings: their role in wound management. Int Wound J. 2006;3(4):282-294

53. Politano AD, Campbell KT, Rosenberger LH, Sawyer RG. Use of silver in the prevention and treatment of infections: silver review. Surg Infect (Larchmt). 2013;14(1):8-20.

54. Hiro ME, Pierpont YN, Ko F, Wright TE, Robson MC, Payne WG. Comparative evaluation of silver-containing antimicrobial dressings on in vitro and in vivo processes of wound healing. Eplasty. 2012;12:e48.

55. Widgerow AD. Nanocrystalline silver, gelatinases and the clinical implications. Burns. 2010;36(7):965-974.

56. Wright JB, Lam K, Buret AG, Olson ME, Burrell RE. Early healing events in a porcine model of contaminated wounds: effects of nanocrystalline silver on matrix metalloproteinases, cell apoptosis, and healing. Wound Repair Regen. 2002;10(3):141-151.

57. Metzmacher I, Ruth $\mathrm{P}$, Abel M, Friess W. In vitro binding of matrix metalloproteinase-2 (MMP-2), MMP-9, and bacterial collagenase on collagenous wound dressings. Wound Repair Regen. 2007;15(4): 549-555.

58. Vasconcelos A, Cavaco-Paulo A. Wound dressings for a proteolytic-rich environment. Appl Microbiol Biotechnol. 2011;90(2):445-460.

59. Weber L, Kirsch E, Müller P, Krieg T. Collagen type distribution and macromolecular organization of connective tissue in different layers of human skin. J Invest Dermatol. 1984;82(2):156-160.
60. Ruszczak Z. Effect of collagen matrices on dermal wound healing. Adv Drug Deliv Rev. 2003;55(12):1595-1611.

61. Elgharably H, Roy S, Khanna S, et al. A modified collagen gel enhances healing outcome in a preclinical swine model of excisional wounds. Wound Repair Regen. 2013;21(3):473-481.

62. Elgharably H, Ganesh K, Dickerson J, et al. A modified collagen gel dressing promotes angiogenesis in a pre-clinical swine model of chronic ischemic wounds. Wound Repair Regen. Epub September 15, 2014.

63. Liu Y, Griffith M, Watsky MA, et al. Properties of porcine and recombinant human collagen matrices for optically clear tissue engineering applications. Biomacromolecules. 2006;7(6):1819-1828.

64. Adhirajan N, Shanmugasundaram N, Shanmuganathan S, Babu M. Collagen-based wound dressing for doxycycline delivery: in-vivo evaluation in an infected excisional wound model in rats. J Pharm Pharmacol. 2009;61(12):1617-1623.

65. Gottrup F, Cullen BM, Karlsmark T, Bischoff-Mikkelsen M, Nisbet L, Gibson MC. Randomized controlled trial on collagen/oxidized regenerated cellulose/silver treatment. Wound Repair Regen. 2013;21(2): 216-225.

66. Dalla Paola L. Diabetic foot wounds: the value of negative pressure wound therapy with instillation. Int Wound J. 2013;10(Suppl 1): 25-31.

67. Orgill DP, Bayer LR. Negative pressure wound therapy: past, present and future. Int Wound J. 2013;10(Suppl 1):15-19.

68. Huang C, Leavitt T, Bayer LR, Orgill DP. Effect of negative pressure wound therapy on wound healing. Curr Probl Surg. 2014;51(7): 301-331.

69. Mouës CM, van Toorenenbergen AW, Heule F, Hop WC, Hovius SE. The role of topical negative pressure in wound repair: expression of biochemical markers in wound fluid during wound healing. Wound Repair Regen. 2008;16(4):488-494.

70. Wiegand C, Hipler UC. A superabsorbent polymer-containing wound dressing efficiently sequesters MMPs and inhibits collagenase activity in vitro. J Mater Sci Mater Med. 2013;24(10):2473-2478.

71. Eming S, Smola H, Hartmann B, et al. The inhibition of matrix metalloproteinase activity in chronic wounds by a polyacrylate superabsorber. Biomaterials. 2008;29(19):2932-2940.

72. Humbert P, Faivre B, Véran Y, et al. Protease-modulating polyacrylate-based hydrogel stimulates wound bed preparation in venous leg ulcers - a randomized controlled trial. J Eur Acad Dermatol Venereol. 2014;28(12):1742-1750.

73. Golub LM. Introduction and background. Pharmacol Res. 2011;63(2): 99-101.

74. Erfurt-Berge C, Renner R. Recent developments in topical wound therapy: impact of antimicrobiological changes and rebalancing the wound milieu. Biomed Res Int. 2014;2014:819525.
Metalloproteinases In Medicine

\section{Publish your work in this journal}

Metalloproteinases In Medicine is an international, peer reviewed, open access journal that aims to provide a platform for the discussion and dissemination of knowledge about the role that metalloproteinases - such as matrix metalloproteinases (MMP), ADAMs, ADAMTSs, and astacins, as well as their inhibitors - play in diseases.

\section{Dovepress}

The manuscript management system is completely online and includes a very quick and fair peer review system, which is all easy to use. Visit http://www.dovepress.com/testimonials.php to read real quotes from published authors. 